\title{
Topografia e irrigação do oviduto da rã-touro Lithobates catesbeianus (Shaw, 1802)
}

\author{
Marcela Cristina Lisboa \\ Caio Henrique de Oliveira Carniatto \\ Rosângela Felipe Rodrigues \\ Alan Peres Ferraz de Melo * \\ Universidade de São Paulo \\ Avenida Prof. Dr. Orlando Marques de Paiva, 87, Cidade Universidade \\ CEP 05508-270, São Paulo $\square$ SP, Brasil \\ * Autor para correspondência \\ alanmelo@usp.br
}

Submetido em 19/06/2013

Aceito para publicação em 21/10/2013

\section{Resumo}

A rã-touro (Lithobates catesbeianus) é uma espécie nativa da América do Norte. Ela pode atingir aproximadamente $20 \mathrm{~cm}$ de comprimento e um peso corpóreo de $500 \mathrm{~g}$. Foram utilizadas 30 rãs adultas da espécie Lithobates catesbeianus em regime de postura para a observação do oviduto. Os animais foram submetidos à eutanásia para o estudo da topografia visceral e distribuição vascular após injeção de látex corado em vermelho no leito arterial. $\mathrm{O}$ oviduto da rã $L$. catesbeianus está situado na cavidade pleuroabdominal, dorsalmente, estendendo-se da região cranial até a região caudal. A irrigação na região do infundíbulo e magno, em ambos os antímeros, é feita pelo ramo arterial do tronco braquiocefálico. O istmo apresenta duas fontes, as artérias cranial e média do oviduto, com exceção da junção próxima ao ovissaco. No istmo e no próprio ovissaco, a irrigação ocorre por meio da artéria caudal do oviduto, que se origina da artéria pudenda.

Palavras-chave: Anatomia; Oviduto; Lithobates catesbeiana; Rã; Vascularização

\section{Abstract}

Oviduct topography and irrigation in the bullfrog Lithobates catesbeianus (Shaw, 1802). The bullfrog (Lithobates catesbeianus) is a species native to North America. It can reach about $20 \mathrm{~cm}$ in length and a body weight of $500 \mathrm{~g}$. We used 30 adult frogs of the species Lithobates catesbeianus laying eggs to observe the oviduct. The animals were euthanized for studying visceral topography and vascular distribution after injection of red stained latex in the arterial bed. Oviduct in the frog L. catesbeianus is located into the pleural abdominal cavity, dorsally, extending from the cranial to the caudal region. Irrigation in the region of infundibulum and magnum, on both antimeres, is made by the arterial branch of the brachiocephalic trunk. Isthmus has two sources, the cranial and medial arteries of the oviduct, except the junction close to the ovisac. In isthmus and in the ovisac itself, irrigation occurs through the caudal artery of the oviduct, which derives from the pudendal artery.

Key words: Anatomy; Frog; Oviduct; Lithobates catesbeianus; Vascularization 


\section{Introdução}

Na produção animal, a criação intensiva de rãs (Anfigranja) tem lugar de destaque e está em fase emergente (LIMA et al., 2003), pois oferece proteína de origem animal de baixo custo. Apesar de ser uma espécie nativa da América do Norte (CUNHA; DELARIVA, 2009), a rã-touro é a espécie mais utilizada nos ranários brasileiros (LIMA et al., 1998), e, por ter se adaptado ao clima tropical, atinge a maturidade sexual em menos de um ano (SOUSA et al., 2010). É a maior espécie de sapo norte-americano, podendo atingir $20 \mathrm{~cm}$ de comprimento (HICKMAN et al., 2013).

As rãs apresentam órgãos genitais distintos das outras espécies (HÖFLING et al., 1995; COSTA et al., 1998). Em anfíbios, o oviduto se encontra paralelo e lateral aos rins, levemente enrolados nas salamandras e muito enrolado em anuros (DUELLMAN; TRUEB, 1994). A abertura do oviduto - infundíbulo é ciliado e localiza-se ao lado do pulmão.

Os ovidutos têm como função transportar os óvulos dos ovários e sustentar o embrião enquanto este está se deslocando (KARDONG, 2010). Produzem, ainda, substâncias associadas ao ovo, como gema e casca (POUGH et al., 2008). Os anfíbios apresentam ovidutos glandulares e convolutos. As porções caudais acrescentam camadas de gelatina aos ovos que são mantidos nos ovissacos (HILDEBRAND; GOSLOW, 2006).

O oviduto caracteriza-se por possuir três ou quatro regiões: a cranial é o ostium ou infundíbulo (parte superior próxima ao fígado), encontrado dilatado sob influência hormonal, quando não tem influência hormonal é tipicamente reto ou encurvado com diâmetro reduzido. A região caudal é o atrium, estreitado e aglandular. A região da ampulla (parte média do tubo) é longa, altamente enrolada e secretora (WAKE; DICKIE, 1998).

O conhecimento pormenorizado da anatomia reprodutiva desta espécie facilitará o manejo reprodutivo em sistemas de criação intensiva. Portanto, objetivou-se estudar a arquitetura vascular, descrever sua distribuição na parede do oviduto, seu padrão fluxográfico e evidenciar ou não anastomoses entre seus diversos ramos no oviduto da rã Lithobates catesbeianus.

\section{Material e Métodos}

Utilizou-se 30 (trinta) rãs adultas da espécie Lithobates catesbeianus, em regime de postura, com peso variando entre 257 e $410 \mathrm{~g}$. Os animais foram coletados no Ranário Bomsalito, Município de Catanduva, Estado de São Paulo, inscrito na Secretaria Estadual de Agricultura - 157/SP, e transferidos para o Laboratório de Anatomia Veterinária do Centro Universitário de Rio Preto (UNIRP), com protocolo de bioética ${ }^{\circ} 883 / 2008$.

No laboratório, os espécimes foram eutanasiados para a visualização do tronco aórtico. A eutanásia ocorreu mediante a administração de $1,2 \mathrm{~mL}$ de tiopental sódico $(1 \mathrm{~g} / 100 \mathrm{ml}=10 \mathrm{mg} / \mathrm{ml})$, por via intracelomática e administração de $3 \mathrm{~mL}$ de cloreto de potássio intracardíaco. Após secção na parede ventral da cavidade celomática, introduziu-se uma cânula no tronco aórtico para injeção de látex corado com pigmento específico. Logo após a injeção do látex ampliou-se a incisão da cavidade celomática para identificação da topografia e irrigação do oviduto.

\section{Resultados}

\section{Topografia do oviduto}

Identificou-se que o oviduto estava localizado na cavidade celomática, dorsalmente, estendendo-se da região cranial até a região caudal mantendo relações anatômicas com todas as vísceras. Devido a esta grande distribuição do oviduto na cavidade celomática, este é divido em infundíbulo, magno e istmo. $\mathrm{O}$ infundíbulo é uma estrutura em forma de funil, apresentando uma abertura: óstio infundibular. Logo após, localizou-se o magno, que se apresentava como a parte mais longa e convoluta do oviduto. $\mathrm{O}$ istmo estava em sequência ao magno, e se apresentava como uma pequena região de fino calibre. Dando continuidade ao oviduto, no seu final próximo a cloaca, encontrava-se o ovissaco, estrutura saculiforme (Figura 1). 
FIGURA 1: Fotomacrografia do oviduto isolado da Lithobates catesbeianus, vista dorsal. Observar o reto (RT) e o oviduto $(\mathrm{O})$, sendo formado pelas seguintes partes: infundíbulo (seta), magno (AT), istmo (AM) e ovissaco $(*)$. Barra: $1 \mathrm{~cm}$.

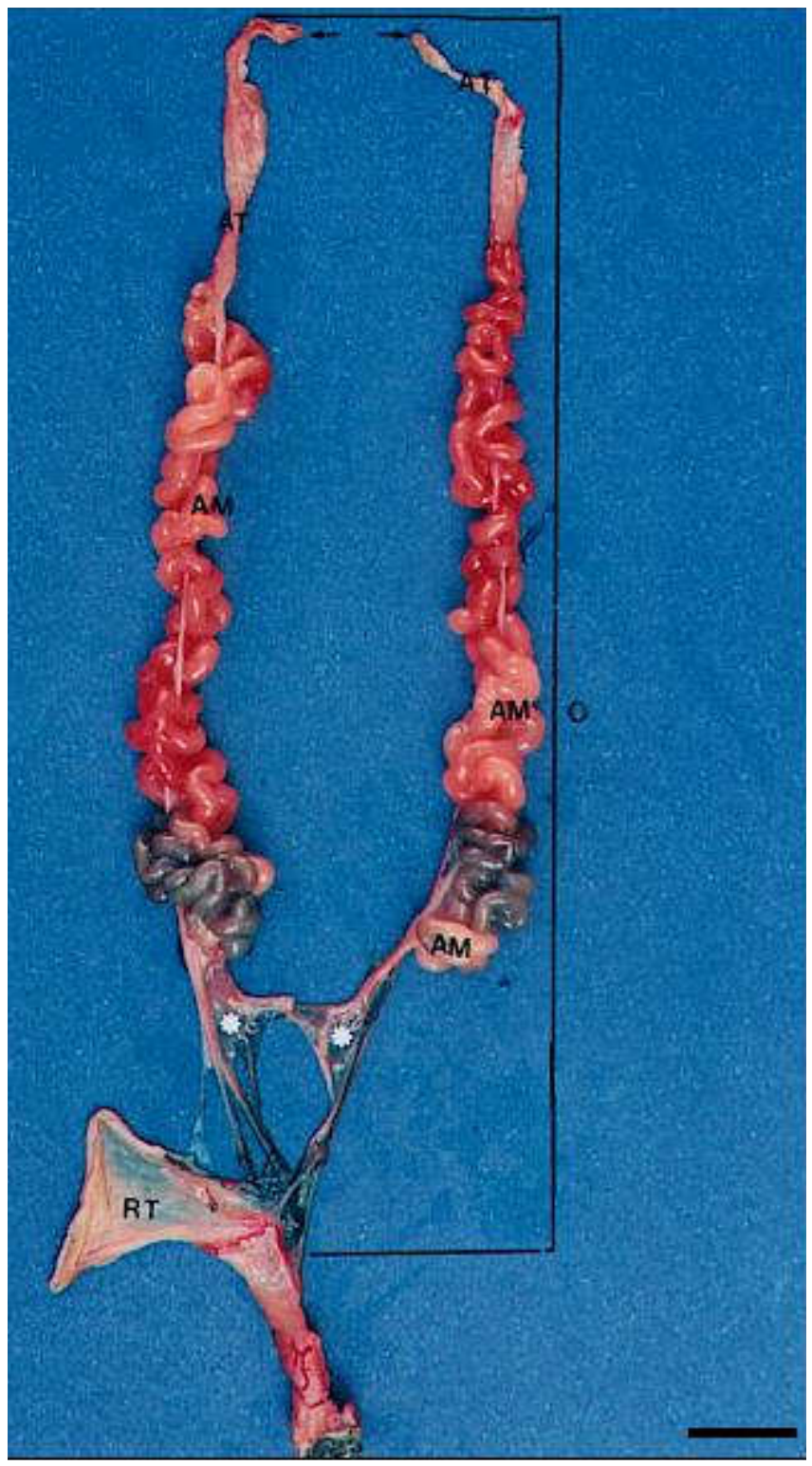

\section{Irrigação do oviduto}

Como o oviduto ocupava desde a região cranial até a região caudal da cavidade celomática, possuía variadas fontes de irrigação. A região do infundíbulo e magno, em ambos os antímeros, era irrigada pelo ramo arterial que se originava do tronco braquiocefálico diretamente em $96,6 \%$ dos casos, ou por ramo originado em tronco comum com vaso que se dirigia ao membro torácico a partir do tronco braquiocefálico, em 3,4\% dos casos. Já o istmo, com exceção da junção próxima ao ovissaco, apresentava irrigação a partir das artérias cranial e média do oviduto.

Quanto à origem da artéria cranial do oviduto, esta poderia apresentar: diretamente da aorta em ambos os antímeros em 13,3\% dos casos, no antímero esquerdo em 13,3\% dos casos. A irrigação poderia ter origem em tronco comum com a artéria renal cranial em ambos os antímeros em 43,3\%, no antímero direito em 10\% ou no antímero esquerdo em $30 \%$ dos casos. Poderia, ainda, estar ausente em ambos os antímeros em 3,3\%, ou ausente somente no antímero esquerdo em $6,6 \%$ ou somente no antímero direito em $30 \%$ dos casos.

Já a artéria média do oviduto originava-se diretamente da aorta em ambos os antímeros em 6,6\% dos animais estudados, somente no antímero direito em 3,3\%. Evidenciou-se, ainda, que poderia apresentar-se em tronco comum com artérias que se dirigem ao rim a partir da aorta em ambos os antímeros em 43,3\%, no antímero direito em $3,3 \%$, ou no antímero esquerdo em 3,3\% dos casos estudados. As duas artérias médias do oviduto apresentavam-se duplas, tendo origem a partir da aorta em 3,3\% dos casos estudados. Em 3,3\%, poderia ainda estar ausente em ambos os antímeros, no antímero direito em $3,3 \%$, ou no antímero esquerdo em $3,3 \%$ (Figuras 2 e 3 ).

Referente ao istmo com o ovissaco e o próprio ovissaco, a irrigação ocorria por meio da artéria caudal do oviduto que se originava da artéria pudenda interna em 96,6\% dos casos. Esta junção em 3,3\% dos casos era irrigada por uma artéria que se originava da artéria ilíaca interna, sendo o ovissaco irrigado pela artéria caudal do oviduto, que apresentava origem na artéria pudenda interna.

Evidenciou-se, ainda, uma artéria que une a artéria cranial do oviduto à artéria média do oviduto. Esta artéria ocupava toda a margem visceral do oviduto (Figura 3). Chamou-se de artéria anastomótica por ser um vaso com esta característica. 
FIGURA 2: Fotomacrografia da cavidade celomática de Lithobates catesbeianus, vista ventral. Observar a aorta direita (AD), aorta esquerda (AE), artérias renais $(*)$, oviduto $(\mathrm{O})$ e ovissaco $(\mathrm{OS})$. Barra: $1 \mathrm{~cm}$.

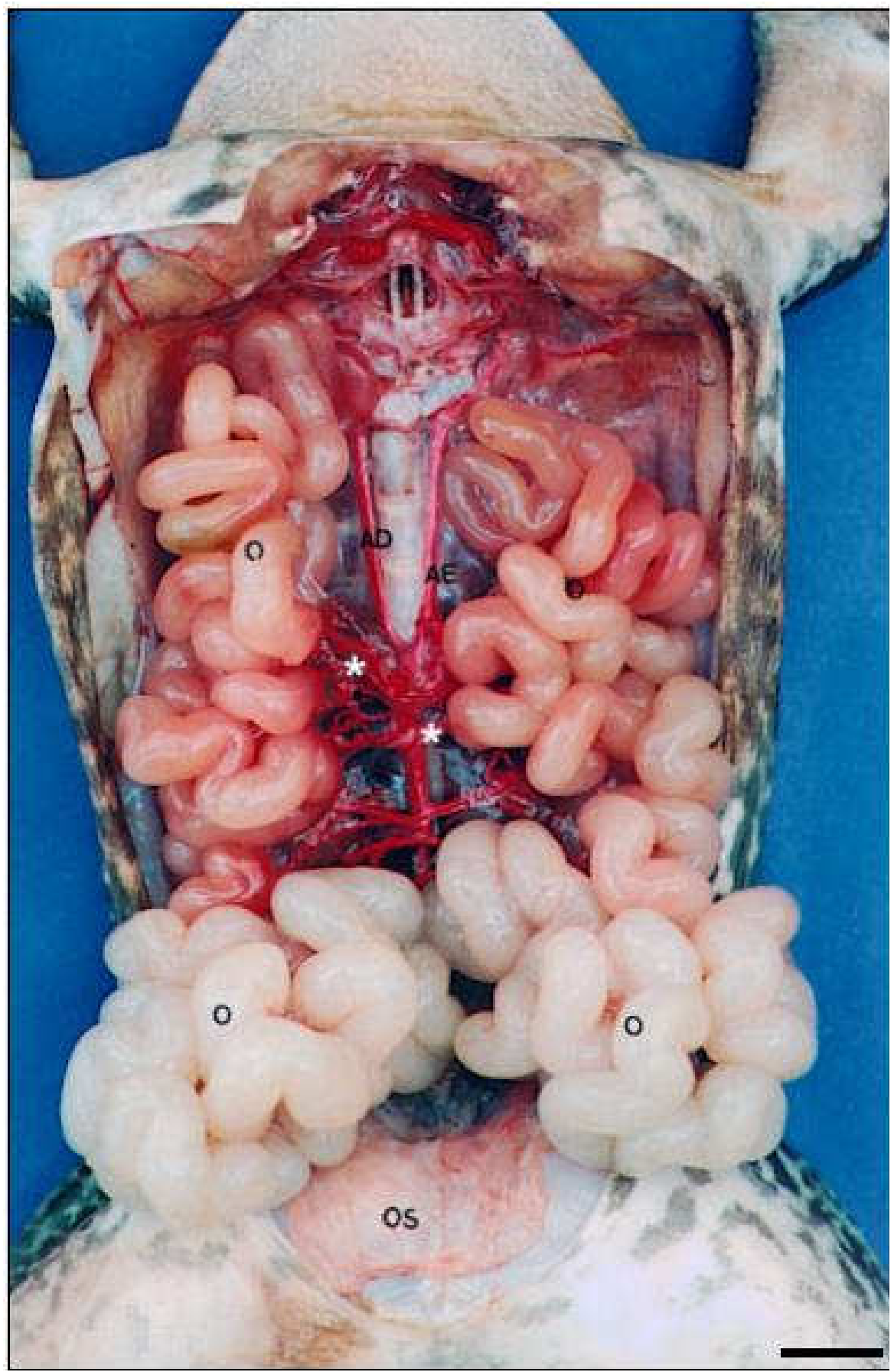


FIGURA 3: Fotomacrografia da cavidade celomática de Lithobates catesbeianus, vista ventral. Observar a aorta direita (AD), a aorta esquerda (AE), os rins (R) e a aorta comum (AC). A aorta comum origina a artéria renal cranial esquerda (seta) que emite artérias para o ovário $(\mathrm{OV})$ e artérias para os rins. Dos ramos que se dirigem aos rins identifica-se as artérias cranial do oviduto (AR) para ambos os antímeros, percorrendo o ligamento dorsal do oviduto (L). No antímero direito a artéria média do oviduto (AM) que se origina a partir de ramos renais $(*)$. Barra: $1 \mathrm{~cm}$.

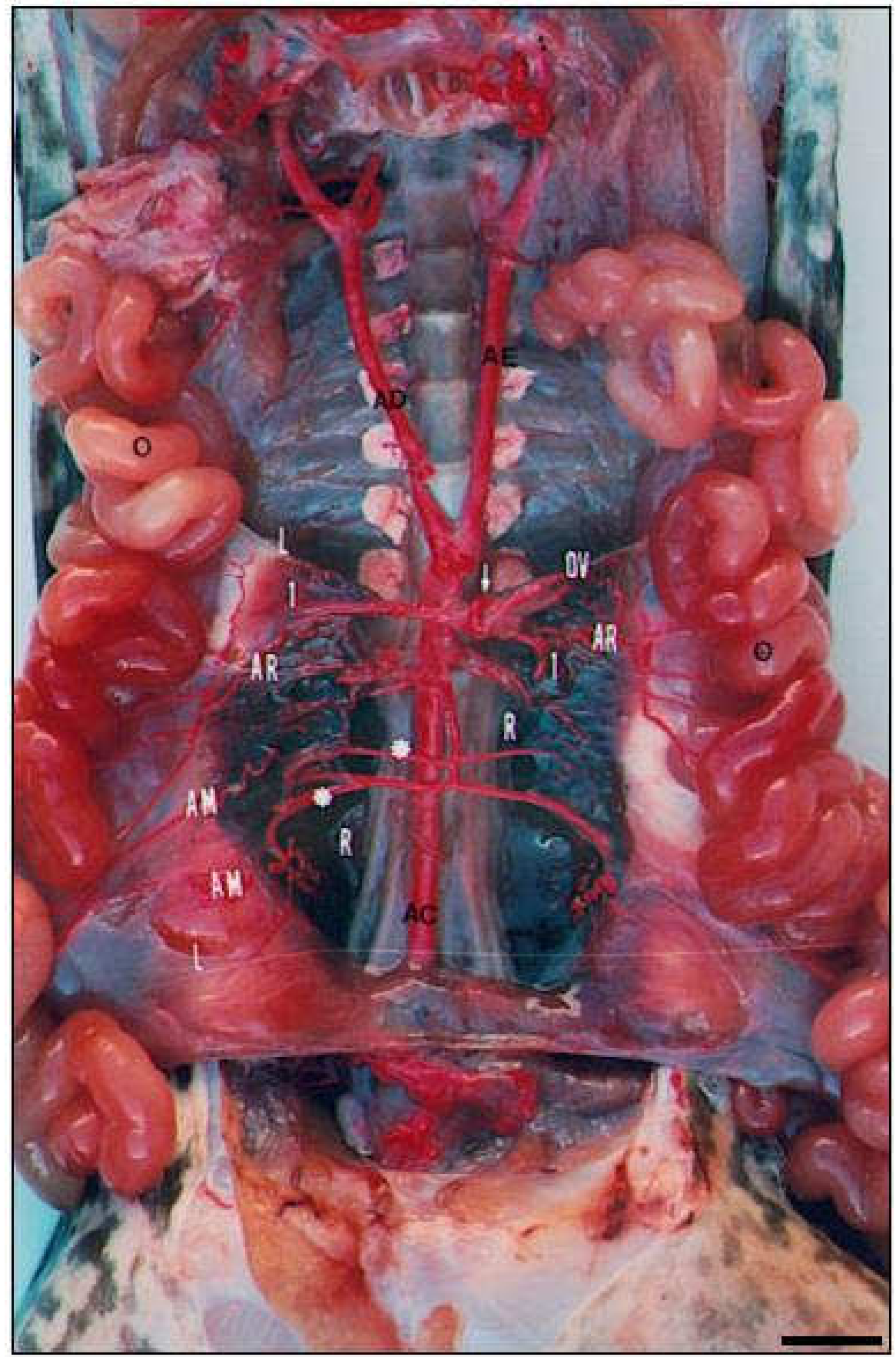




\section{Discussão}

Para melhor segurança quanto à nomenclatura das estruturas presentes no oviduto das rãs estudadas, preferiu-se seguir a nomenclatura de Baumel (1993) mesmo sabendo que esta descreve somente estruturas presentes em aves, por se entender que há uma semelhança maior, em aspectos gerais, entre anfíbios e aves do que entre anfíbios e mamíferos.

Observou-se que o oviduto das rãs apresenta-se desenvolvido bilateralmente com função ativa. Nickel et al. (1977) relatam que o oviduto é duplo na fase embrionária e impar somente no antímero esquerdo nas aves adultas. Montagna (1959), Duellman e Trueb (1994), Usinger et al. (1995), Costa et al. (1998) e Almeida-Santos e Orsi (2002) também descrevem que o oviduto apresentase nos dois antímeros. Nestes animais há uma simetria entre os ovidutos, diferente das descrições de AlmeidaSantos e Orsi (2002) para as jararacas Brothops jararaca. Warren e Walker (1987), estudando répteis, Duellman e Trueb (1994), estudando anfíbios, e Costa et al. (1998), estudando rãs, relatam que o oviduto destes animais apresenta-se enovelado ou enrolado, a semelhança do que foi evidenciado na espécie estudada.

Quanto à divisão do oviduto em partes, ocorre uma divergência de nomenclatura quando comparada com Wake e Dickie (1998). Estes dividem o oviduto de anfíbio em ostium, atrium e ampulla. Preferiu-se nomeálo como infundíbulo, magno, istmo, da mesma maneira que sugere o trabalho de Baumel (1993), e por diversos outros autores como Nickel et al. (1977), King (1986) e Dyce et al. (1991).

Nas rãs estudadas o infundíbulo assemelha-se a um funil e apresenta-se como a primeira parte do oviduto. Este fato também evidenciado por Nickel et al. (1977), Romer e Parsons (1985), Dyce et al. (1991), Baumel (1993) e Almeida-Santos e Orsi (2002). O magno apresenta-se como a parte mais longa do oviduto, como demonstra Baumel (1993). Almeida-Santos e Orsi (2002) não mencionam sobre o magno em suas descrições anatômicas. Quanto ao istmo apresentar diâmetro reduzido, somente Nickel et al. (1977) e Baumel (1993) relatam. Já a estrutura final do oviduto, o ovissaco, não está descrita por Baumel (1993), mas presente nas descrições de Romer e Parsons (1985), Costa et al. (1998), Hildebrand e Goslow (2006). Optouse pela nomenclatura de ovissaco e não de útero, como alude Costa et al. (1998), por se entender que não seria um útero, mas somente um depósito de ovo, como se referem Romer e Parsons (1985).

No material estudado, constatou-se que as regiões do infundibulum e magnum são irrigadas pelo ramo arterial que se origina do tronco braquiocefálico diretamente. Somente Baumel (1986) relata que o oviduto de aves é irrigado por uma artéria cranial que possui origem a partir da artéria renal cranial, por uma artéria média que é inconstante e origina-se da artéria ilíaca, e por uma artéria caudal do oviduto que se origina da artéria pudenda. Todas estas afirmações puderam ser observadas nas rãs estudadas. Estes relatos confirmam, ainda mais, a semelhança que há entre a irrigação do oviduto das rãs e das aves.

A partir dos resultados, foi possível concluir que o oviduto da L. catesbeianus está situado na cavidade celomática, dorsalmente, estendendo-se da região cranial a região caudal. O oviduto está dividido em infundíbulo, magno e istmo.

A irrigação na região do infundíbulo e magno, em ambos os antímeros, ocorre pelo ramo arterial que se origina do tronco braquiocefálico. $\mathrm{O}$ istmo apresenta duas fontes de irrigação que são as artérias cranial e média do oviduto, com exceção da junção próxima ao ovissaco. No istmo e no próprio ovissaco, a irrigação ocorre através da artéria caudal do oviduto que se origina da artéria pudenda.

\section{Agradecimentos}

Os autores agradecem ao auxílio financeiro da FAPESP (processo 01/12004-3) e pela colaboração do Sr. Gilmar Rodrigues Lopes, técnico de laboratório do Centro Universitário de Rio Preto (UNIRP).

\section{Referências}

ALMEIDA-SANTOS, S. M.; ORSI, A. M. Ciclo reprodutivo de Crotalus durissus e Brothops jararaca (Serpente, Viperidae): 
Morfologia e função do oviduto. Revista Brasileira de Reprodução Animal, Belo Horizonte, v. 26, n. 2, p. 109-12, 2002.

BAUMEL, J. J. Coração e vasos sanguíneos das aves. In: GETTY, R. (Ed.). Anatomia dos animais domésticos. Vol. 2. 5 ed. Rio de Janeiro: Guanabara Koogan, 1986. p. 1842-1880.

BAUMEL, J. J. (Ed.) Nomina Anatomica Avium. 2 ed. Cambridge, Massachusetts: Club, 1993. 46 p.

COSTA, C. L. S.; LIMA, S. L.; ANDRADE, D. R.; AGOSTINHO, C. A. Caracterização morfológica dos estágios de desenvolvimento do aparelho reprodutor feminino da rã-touro, Rana catesbeiana, no sistema de anfigranja de criação intensiva. Revista Brasileira de Zootecnia, Viçosa, v. 27, n. 4, p. 651-657, 1998.

CUNHA, E. R.; DELARIVA, R. L. Introdução da rã-touro, Lithobates catesbeianus (SHAW, 1802): uma revisão. SaBios: Revista de Saúde e Biologia, Campo Mourão, v. 4, n. 2, p. 34-46, 2009.

DUELLMAN, W. E.; TRUEB, L. Biology of amphibians. Baltimore: The Johns Hopkins University Press, 1994. 670 p.

DYCE, K. M.; SACK, W. O.; WENSING, C. J. G. O Aparelho urogenital. In: DYCE, K. M.; SACK, W. O.; WENSING, C. J. G. (Ed.). Tratado de anatomia veterinária. 2 ed. Rio de Janeiro: Guanabara, 1991.p. 1411-1493.

HICKMAN, C. P.; ROBERTS, L. S.; KEEN, S. L.; EISENHOUR, D. J.; LARSON, A.; L'ANSON, H. Princípios integrados de Zoologia. 15 ed. Rio de Janeiro: Guanabara Koogan, 2013. 872 p.

HILDEBRAND, M.; GOSLOW, G. Análise da estrutura dos vertebrados. 2 ed. São Paulo: Atheneu, 2006. 632 p.

HÖFLING, E.; OLIVEIRA, A. M. S.; RODRIGUES, M. T.; TRAJANO, E.; ROCHA, P. L. B.; Chordata: manual para um curso prático. São Paulo: Editora da Universidade de São Paulo, 1995. $242 \mathrm{p}$

KARDONG, K. V. Vertebrados: anatomia comparada, função e evolução. São Paulo: Roca, 2010. 913 p.
KING, A. S. Aparelho urogenital das aves. In: GETTY, R. (Ed.). Anatomia dos animais domésticos. Vol. 2. 5 ed. Rio de Janeiro: Guanabara Koogan, 1986. p. 1813-1828.

LIMA, S. L.; COSTA, C. L. S.; AGOSTINHO, C. A.; ANDRADE, D. R.; PEREIRA FILHO, H. P. Estimativa do tamanho da primeira maturação sexual da rã-touro, Rana catesbeiana, no Sistema Anfigranja de Criação Intensiva. Revista Brasileira de Zootecnia, Viçosa, v. 27, n. 3, p. 416-420, 1998.

LIMA, S. M.; CASALI, A. P.; AGOSTINHO, C. A. Desempenho zootécnico e tabela de alimentação de girinos de rã-touro (Rana catesbeiana) criados no sistema anfigranja. Revista Brasileira de Zootecnia, Viçosa, v. 32, n. 3, p. 512-518, 2003.

MONTAGNA, W. Comparative anatomy. New York: John Wiley \& Sons, 1959. 397 p.

NICKEL, R.; SCHUMMER, A.; SEIFERLE, E. Anatomy of the domestic birds. Vol. 5. Berlin: Paul Parey, 1977. 214 p.

POUGH, F. H.; JANIS, C. M.; HEISER, J. B. A vida dos vertebrados. 4 ed. São Paulo: Atheneu, 2008. 684 p.

ROMER, S. A.; PARSONS, S. T. Anatomia comparada dos vertebrados. São Paulo: Atheneu, 1985. 560 p.

SOUSA, R. M. R.; AGOSTINHO, C. A.; OLIVEIRA, F. A.; ARGENTIM, D.; OLIVEIRA, L. C.; WECHSLER, F. S.; AGOSTINHO, S. M. M. Recria de rã-touro (Rana catesbeiana) em tanques-rede alojados em viveiros de tilápia. Archivos de Zootecnia, Córdoba, v. 59, n. 225, p. 31-38, 2010.

USINGER, R. L.; STORER, T. I.; STEBBINS, R. C. Zoologia geral. 6 ed. São Paulo: Companhia Editora Nacional, 2000. 627 p.

WAKE, M. H.; DICKIE, R. Oviduct structure and function and reproductive modes in amphibians. Journal of Experimental Zoology, New York, v. 282, n. 4-5, p. 477-504, 1998.

WARREN, F.; WALKER, J. R. Function anatomy of the vertebrates an evolution perspective. Rio de Janeiro: Saunders College, 1987. 864 p. 